\title{
Formação universitária e trabalho: áreas de atuação desejadas por estudantes de educação física
}

\author{
University education and work: areas of activity desired by Physical Education students
}

Formación universitaria y trabajo: áreas de actuación deseadas por académicos de educación física

Andrea Maria Lobo, Glhevysson dos Santos Barros ${ }^{\mathrm{II}}$, Paulo Sérgio Pimentel de Oliveira ${ }^{\mathrm{III}}$, Felipe da Silva Triani ${ }^{\mathrm{IV}}$

\section{Resumo}

O Profissional de Educação Física é habilitado para atuar na orientação do Esporte, da Atividade Física e da Educação Física. O objetivo deste trabalho foi identificar quais áreas os estudantes de bacharelado em educação física desejam atuar. Foi realizada uma pesquisa qualitativa, tendo o questionário como instrumento de coleta de dados, sendo respondido por 92 estudantes. Foi possível identificar que 66\% dos estudantes desejam atuar em academia de ginástica. $\mathrm{O}$ estudo concluiu que há necessidade de refletir sobre os campos de atuação, pois enquanto grande parte dos estudantes deseja o mesmo campo, outras áreas carecem de profissionais qualificados para atuar.

Palavras-chave: Ciências da Saúde; Capacitação de Professores; Mercado de trabalho; Treinamento de Resistência

\begin{abstract}
The Physical Education Professional is qualified to act in the Sports, Physical Activity and Physical Education orientation. The objective of this work was to identify which areas the Physical Education students wish to work. A qualitative research was carried out, with the questionnaire as a data collection instrument, being answered by 92 students. It was possible to identify that $66 \%$ of the students wish to work in fitness center. The study concluded that there is a need to reflect on the fields of activity, because while most students want the same field, other areas lack qualified professionals to acting.
\end{abstract}

Keywords: Health Sciences; Teacher Training; Job Market; Resistance Training

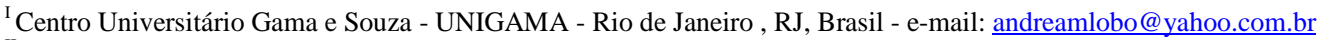

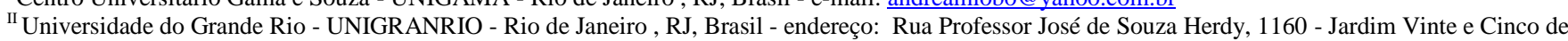
Agosto, Duque de Caxias - RJ, CEP: 25071-202. - e-mail: guersonbarros@gmail.com

${ }^{\text {III }}$ Centro Universitário Gama e Souza - UNIGAMA - Rio de Janeiro, RJ, Brasil - e-mail: paulopimentelgem@ @mail.com

${ }^{\text {IV }}$ Centro Universitário Gama e Souza - UNIGAMA - Rio de Janeiro, RJ, Brasil - e-mail: felipetriani@gmail.com 


\section{Resumen}

El Profesional de Educación Física está habilitado para actuar en la orientación del Deporte, de la Actividad Física y de la Educación Física. El objetivo de este trabajo fue identificar en qué áreas quieren actuar los estudiantes de educación física (bacharelado). Se realizó una investigación cualitativa, teniendo el cuestionario como instrumento de recolección de datos, siendo respondido por 92 estudiantes. Fue posible identificar que el $66 \%$ de los estudiantes desean actuar en el gimnasio. El estudio concluyó que es necesario reflexionar sobre los campos de actuación, pues mientras gran parte de los estudiantes desea el mismo campo, otras áreas carecen de profesionales calificados para actuar.

Palabras clave: Ciencias de la Salud; Formación del Profesorado; Mercado de Trabajo; Entrenamiento de Resistencia

\section{Introdução}

A educação física é uma profissão em constante crescimento no mercado de trabalho. Nela o profissional pode atuar na área escolar, quando licenciado, e no ambiente fora da escola, quando bacharel. Além de ser fundamental enquanto área da saúde, atualmente também tem conquistado destaque na sociedade pelo movimento de valorização do corpo, no qual o exercício físico tem função importante (RIBEIRO, 2008).

A profissão foi regulamentada em 1998 por meio da lei 9696, que proporcionou a criação do Conselho Federal de Educação Física (CONFEF) e o Conselho Regional de Educação Física (CREF), tendo como objetivo realizar ações para melhoria da qualidade profissional e adimplente com suas obrigações estatutárias, possibilitando melhor atendimento a sociedade (BRASIL, 1998).

A regulamentação da profissão, de acordo com Nozaki (2004), implicou um reordenamento do campo profissional. Esse fato contribuiu para o início da reestruturação curricular, pois abriu portas para a distinção da própria área, distinguindo-a em licenciatura e bacharelado. Dessa maneira, inicialmente a Resolução CFE 03/1987 (BRASIL, 1987), estabelecia que o profissional de Educação Física ao final de quatro anos teria nível superior e o título de bacharel e/ou licenciatura. No entanto, com a mudança na legislação, o Parecer CNE 9/2001 anulou o contido na resolução anterior no que se tratava da possibilidade de obtenção de diploma com bacharelado e licenciatura simultânea. Desse modo, o curso de licenciatura passou a ter terminalidade e integralidade própria em relação ao bacharelado, constituindo-se em um projeto específico, com identidades curriculares distintas.

Já a resolução CNE/CES 07/2004 instituiu as Diretrizes Curriculares Nacionais para os cursos de graduação em Educação Física, em nível superior de graduação plena, estabelecendo orientações específicas para a licenciatura plena em Educação Física. $\mathrm{O}$ artigo segundo define que: 
Para a formação de graduados em Educação Física definem os princípios, as condições e os procedimentos para a formação dos profissionais de Educação Física, estabelecidos pela Câmara de Educação Superior do Conselho Nacional de Educação, para aplicação em âmbito nacional na organização, no desenvolvimento e na avaliação do projeto pedagógico dos cursos de graduação em Educação Física das Instituições do Sistema de Ensino Superior.

O artigo quarto da resolução CNE/CES 07/2004 ainda estabelece que "o curso de graduação em Educação Física deverá assegurar uma formação generalista, humanista e crítica, qualificadora da intervenção acadêmico-profissional, fundamentada no rigor científico, na reflexão filosófica e na conduta ética".

Dessa forma, somente com a emergência das Resoluções 1 e 2 de 2002 (BRASIL, 2002), foi apontada a necessidade de implementação, até o ano de 2005, de novos projetos pedagógicos, com adequação dos currículos dos cursos de licenciatura. Nessa perspectiva, os estudantes que almejavam o título de licenciado deveriam cursar a graduação em tempo mínimo de três anos, em 6 período, tendo como carga horária 2800 horas, sendo 400 de estágio, formação essa que permitiria o intitulado atuar em toda a educação básica.

No entanto, houve uma mudança quanto à formação inicial de professores de educação básica sobre a Formação Inicial de docentes para a educação básica em nível superior, em cursos de licenciatura. Segundo o Parecer 02/2015 do Conselho Nacional de Educação, em cursos de licenciatura, organizados em áreas especializadas, por componente curricular, estruturam-se por meio da garantia de base comum nacional das orientações curriculares, constituindo-se de, no mínimo: 3.200 (três mil e duzentas) horas de efetivo trabalho acadêmico, em cursos com duração de, no mínimo, 8 (oito) semestres ou 4 (quatro) anos (BRASIL, 2015).

O ano de 2015 cria uma nova marca na história da formação na área, no momento em que é publicado o Parecer 2/2015 (BRASIL, 2015). O referido documento assinala que os cursos de licenciatura quando forem uma segunda graduação, por profissionais já licenciados, poderão ter uma carga horária mínima variável entre 800 e 1200 horas, dependendo da equivalência com a primeira formação. Ainda nessa perspectiva, para aqueles não licenciados que tenham interesse em cursar licenciatura em educação física, poderá cursar a formação em uma carga horária mínima variável entre 1000 horas e 1400 horas, também dependendo da equivalência entre o curso de origem e o currículo da instituição pretendida (BRASIL, 2015).

Assim, na licenciatura, o profissional é habilitado a atuar nas escolas. Já no bacharelado, o profissional pode atuar em ambientes não formais de ensino (ANTUNES, 2007). Dessa maneira, de acordo com o Estatuto do CONFEF (2010), logo em seu artigo $9^{\circ}$, é apontado o campo de atuação que 
cabe ao formado em Educação Física, sendo considerado um especialista em atividade física e apto para exercer atuação no esporte, ginástica, lutas, danças, musculação, jogos, atividade laboral, sendo de sua competência a prestação de serviço no desenvolvimento da saúde e educação.

Diante desses entendimentos, é possível perceber a ampla possibilidade de atuação profissional destinada àqueles que escolhem o bacharelado em Educação Física. No entanto, embora as possibilidades sejam múltiplas, pelo fato dos ingressantes, em sua maioria, serem praticantes de musculação (SOUZA; BASTOS; OLIVEIRA, 2014), prática atualmente hegemônica entre estudantes de Educação Física na cidade do Rio de Janeiro (PALMA et al., 2007), o pressuposto é o de que a maioria dos estudantes deseja atuar nessa área. Portanto, o objetivo deste estudo foi conhecer quais são as áreas de atuação profissional que os estudantes de Educação Física de uma universidade privada localizada na zona oeste do Rio de Janeiro desejam atuar após a conclusão da formação.

\section{Metodologia}

A fim de atingir o objetivo pretendido, foi realizada uma pesquisa de campo que, de acordo com Severino (2007), trata-se de uma técnica de aproximação de dados. Nela o pesquisador está presente no ambiente próprio no qual os fenômenos ocorrem. Nesse sentido, a abordagem pretendida foi do tipo qualitativa, embora se tenha utilizado dados quantitativos, principalmente na elaboração de ilustrativo, a intencionalidade não está somente na apresentação dos dados numericamente representativos, mas na implicação social que representa para os participantes do estudo.

Participaram da investigação 92 estudantes de um curso de bacharelado em Educação Física de uma Faculdade privada na zona oeste da cidade do Rio de Janeiro. A escolha foi aleatória e estudantes de diferentes períodos compuseram o grupo amostral. Cabe assinalar que o currículo do curso em questão visa como objetivo um egresso que ocupe o espaço no mercado de trabalho do entorno, local que é caracterizado pelo grande número de academias de ginástica e espaços outdoor para a prática de atividade física, como praias e praças como barras e paralelas.

Tabela 1. Caracterização da amostra

\begin{tabular}{c|c|c}
\hline Média de Idade & Sexo & N \\
\hline 26 anos & $\mathrm{F}$ & 25 \\
\cline { 2 - 3 } & $\mathrm{M}$ & 67 \\
\hline
\end{tabular}

Fonte: elaborado por autores

Como instrumento de coleta de dados foi utilizado um questionário estruturado (SEVERINO, 2007; VELOSO, 2011) com questões abertas e fechadas, tendo como principais perguntas a área de 
atuação em que os estudantes, futuros profissionais de Educação Física, desejam atuar, bem como os motivos que implicaram ou influenciam a escolha.

O tratamento dos dados concernentes aos motivos da escolha pela área de atuação se deu por análise de conteúdo, conforme proposto por Bardin (2016), que sugere a categorização dos resultados em categorias de análise. Dessa maneira, os diferentes motivos descritos pelos estudantes foram agrupados em 8 categorias criadas por semelhança.

Todos os estudantes que participaram da pesquisa assinaram antes de começar o Termo de Compromisso Livre e Esclarecido (TCLE). Além disso, cabe ressaltar que o projeto de pesquisa foi avaliado pelo Comitê de Ética em Pesquisa (CEP), da Universidade do Grande Rio - UNIGRANRIO, sob guarda do CAAE de número nº 61550916.1.0000.5283.

\section{Resultados}

Para ilustrar os resultados obtidos no presente estudo é apresentada a Figura 1 como referência a área de atuação que os estudantes desejam atuar.

Figura 1. Áreas de atuação que os estudantes entrevistados desejam atuar

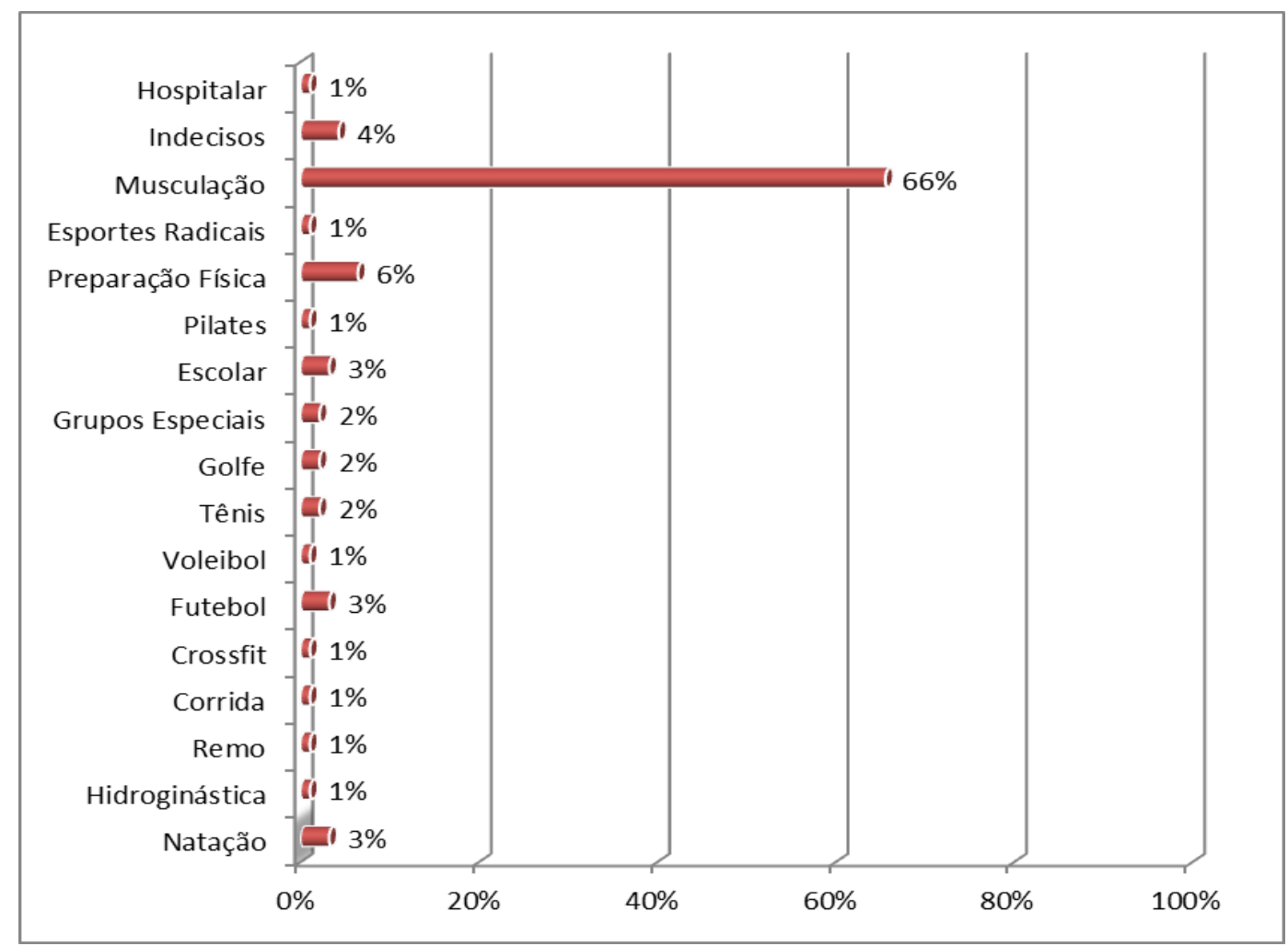

Fonte: elaborado por autores 
Os motivos que influenciam na escolha da área que os estudantes têm interesse de atuar foram distribuídos em 8 categorias para sintetizar os resultados encontrados, conforme ilustra a Tabela 2.

Tabela 2. Motivos pela escolha da área

\begin{tabular}{c|c}
\hline $\mathbf{N}$ & Motivo \\
\hline 66 & Escolheram por identificação na área \\
\hline 10 & Transformar Vidas \\
\hline 9 & Interesse por conhecimento \\
\hline 4 & Já atuar na área \\
\hline 2 & Crescimento do Mercado \\
\hline 2 & Maior remuneração \\
\hline 1 & Ser dono de academia \\
\hline 1 & Ter mais oportunidades \\
\hline
\end{tabular}

Fonte: elaborado por autores

Já a Tabela 2 apresenta dados interessantes, pois verifica que um dos motivos de escolha desses participantes é a identificação na área.

\section{Discussão}

Como nos mostra a Figura 1, apesar de haver diversas opções no campo de atuação do profissional de Educação Física, a área que há maior destaque foi o da musculação. Um dos motivos que os alunos alegaram foi pela identificação deles com esse esporte, visto que muitos realizam estágios durante o período da faculdade, que facilita muitas vezes seu ingresso no mercado de trabalho devido à oportunidade que muitas vezes ganham por conhecerem o ambiente que trabalham.

Com relação à área de atuação dos estudantes, como mostra a Figura 1, a maioria dos participantes escolheu a musculação com $66 \%$ como a área que preferem atuar no mercado de trabalho depois de formado, sob o conceito de que é uma atividade física desenvolvida predominantemente através de exercícios analíticos, utilizando resistência progressiva, fornecida por recursos materiais como: alteres, barras, anilhas, aglomerados, módulos, extensores, pecas lastradas, o próprio corpo e seus seguimentos (FREITAS , 2013).

Segundo Simon (2007), a musculação é um exercício contra a resistência, e na maioria das vezes é realizado com pesos, não sendo uma modalidade esportiva e sim uma forma de treinamento físico. 
Devido as suas qualidades, a musculação passou a ocupar lugar de destaque nas academias, em que o objetivo é a prática regular de exercício físico, tanto para qualidade de vida quanto para a preparação esportiva. A musculação é o tipo de exercício que pode ser realizado por meio de pesos livres e aparelhos, podendo ser praticado por pessoas de diversas idades e com diferentes objetivos. O treinamento com o peso auxilia no emagrecimento, no gasto calórico diário e estimula o metabolismo, prevenindo doenças (SIMON, 2007).

Segundo Freitas (2013), a musculação é uma das modalidades mais praticadas na atualidade, permitindo ao praticante uma melhora no desempenho, na saúde física e mental. Com o crescimento da procura por essa modalidade e o crescimento da população ativa, o papel do profissional de Educação Física ganhou destaque como preparador físico qualificado atuante na área.

Ressalta-se ainda que na sala de musculação o profissional de Educação Física é responsável por prescrever, orientar e acompanhar a todos aqueles que se interessam no âmbito da prática de atividade física, assim sendo também responsável pela promoção de saúde (FREITAS, 2013). Monteiro (2006) acrescenta que o professor é o profissional mais capacitado para prescrever e orientar um exercício físico.

No entanto, em um estudo realizado por Palma et al. (2007) com profissionais de Educação Física atuantes em academias de ginástica, com idade entre 22 a 47 anos de idade, sendo 110 (73,8\%) do sexo masculino e $39(26,2 \%)$ do sexo feminino, constatou-se que: os homens trabalham mais que as mulheres tendo como média com relação a horas semanais de trabalho de 45,5 para homens e 35,6 para mulheres. Já com relação à remuneração, dos 149 respondentes do questionário, 12 disseram que ganham até R\$ 960,00, sendo 3 homens e 9 mulheres; 43 disseram que ganham entre R\$961,00 até R\$1920,00, sendo 32 homens e 11 mulheres; 26 disseram que ganham entre 1921,00 até 2480,00, sendo19 homens e 7 mulheres; e 48 professores disseram que ganham acima de 2481,00, sendo 56 homens e 12 mulheres.

Percebe-se no estudo acima que quanto mais se trabalha, mais ganha, visto que a remuneração desses profissionais nas academias é paga em hora/aula. Ressalta-se no estudo que mais da metade dos profissionais tem mais de um emprego (academias, escolas, etc). Segundo os autores, alguns professores chegam a realizar até 78 horas semanais de trabalho, podendo no futuro repercutir de forma negativa sobre a saúde desses profissionais devido aos estresses e às altas cargas de trabalhos semanais. Dessa forma, comparado aos nossos resultados, em que a maioria tem um foco maior na musculação, é preciso de fato pensar se vale a pena trabalhar tanto para ganhar o que de fato é pago nas salas de musculação das academias. Será que vale a pena ganhar esse valor pela quantidade de anos que foi dedicado aos estudos? Será que terei disposição para trabalhar até a aposentadoria? São diversas dúvidas que é preciso repensar quanto à área de atuação desses futuros profissionais. 
Em outro estudo realizado por Ribeiro (2008), que o objetivo também foi verificar o campo de atuação dos 150 egressos no curso de Educação física da UNIVAP para atuação no mercado de trabalho, entre os anos de 2004 e 2007, foi constatado nas entrevistas sobre as áreas que esses profissionais gostariam de atuar, e foram obtidos os seguintes resultados: Academias (36\%), área Esportiva (16\%), Educacional (15\%), Lazer (7\%), Saúde (4\%) e área acadêmica (3\%). O fato dos ingressantes escolherem a musculação como área de atuação é devido ao grande crescimento das academias de ginástica em todo o Brasil. Segundo o autor, "nos últimos anos a indústria da estética, beleza, cosméticos, cirurgias plásticas, vem crescendo rapidamente, na mesma perspectiva, montar uma academia pode ser um negócio promissor" (p. 02). Em relação ao estudo realizado, percebe-se que os estudantes que participaram da pesquisa também optaram pelas academias como áreas de atuação no mercado de trabalho, visto que é uma área que possibilita seu ingresso mais rapidamente.

Como visto, o campo de trabalho de um profissional de Educação Física é bastante amplo como nos demonstra a Figura 1. No entanto, historicamente, sua inserção se origina na escola com a educação física escolar, e no Brasil sua presença ocorreu durante o século XIX, e desde essa época tem permanecido na cultura escolar (VAGO, 1999). Segundo o autor, era necessário realizar uma revolução moral e higiênica.

Para Nozaki (2004), embora a Educação Física escolar esteja sendo desvalorizada ao longo de vários anos, as práticas corporais externas ao âmbito escolar, tais como as atividades em academias e clubes desportivos, parecem se valorizar.

Essa valorização faz com que os alunos de graduação procurem outras áreas de atuação, além da escolar, como é o caso da musculação. É possível ainda identificar as escolas de esporte e dança, os clubes esportivos, a preparação físico-desportiva, as instituições de reabilitação como espaços onde os professores de educação física atuam (PRONI, 2010).

Dessa maneira, algumas pesquisas, de caráter científico duvidoso, tentaram em dado momento histórico justificar a criação do curso de bacharelado considerando a possibilidade de maior remuneração em decorrência do ganho por hora trabalhada e a maior dedicação a esse segmento (NOZAKI, 2004).

Contudo, desconsideraram que o trabalho nas academias e clubes desportivos, frequentemente, é precarizado, desregulamentado e temporário. Essa situação, portanto, facilita a intensificação da exploração da força de trabalho. Ademais, a situação se agrava quando se percebe que a reorganização técnica do trabalho impôs novos desafios ao profissional de educação física que atua em academias de ginástica, tais como, a facilidade de trabalho em equipe, a comunicabilidade, a iniciativa para a tomada de 
decisão, a responsabilidade pessoal sobre a frequência dos alunos, o conhecimento tecnológico, entre outros aspectos como a busca de qualidade de vida (NOZAKI, 2004).

O termo "qualidade de vida" engloba diversos aspectos da vida de uma pessoa, tendo em vista a população em geral. Do ponto de vista emocional, essa expressão é feita a uma pessoa que tem um grau de satisfação elevado com a vida. Segundo Nahas (2001), a qualidade de vida pode ser desenvolvida em diferentes aspectos do cotidiano, em relação aos parâmetros: sócio-ambientais (moradia, transporte, segurança, assistência médica, trabalho e remuneração, educação, lazer, meio ambiente saudável) e individuais (hereditariedade, hábitos alimentares, controle de estresse, atividade física e comportamento preventivo). Para que um indivíduo tenha uma boa qualidade de vida é necessário que ele tenha saúde, que segundo a Organização Mundial de Saúde (OMS), significa bem-estar físico, social e psíquico.

Assim, a escolha pelo campo de atuação profissional é resultado de múltiplas determinações, dentre elas, a formação inicial é parte importante. Porém, ao mesmo tempo, o campo de atuação profissional não é simplesmente resultado de uma escolha, mas também de condições e oportunidades encontradas pelo egresso no mercado de trabalho.

\section{Conclusão}

Embora a Educação Física tenha uma vasta área de mercado de trabalho e vários seguimentos, a academia é a opção mais procurada como atividade profissional principal devido à facilidade de ingresso no mercado de trabalho. Essa grande procura pode estar associada ao fato de que grande parte dos estudantes do curso de bacharelado em Educação Física são praticantes de musculação e/ou de alguma atividade afim dentro da academia, ou ainda pela facilidade de ingressar no mercado de trabalho.

A valorização da estética e da imagem pessoal, também pode influenciar a procura pela atividade de musculação como exercício físico, e como atividade de trabalho. Dessa maneira, apesar da Educação Física apresentar um mercado de trabalho bastante amplo como nos mostrou o estudo, a musculação, em especial, é a área que mais dá oportunidade de emprego rápido, além desses alunos se identificarem com essa atividade física.

\section{Referências}

ANTUNES, A. C. Mercado de trabalho de trabalho e educação física: aspectos da preparação profissional. Motriz, Rio Claro, SP, v. 10, n. 10, p. 141-149, 2007.

${ }^{1}$ Percepção de bem-estar, refletido em aspectos pessoais, socioculturais, ambientais e econômicos (NAHAS, 2001). 
BARDIN, Laurence. Análise de Conteúdo. São Paulo: Edições 70, 2016.

BRASIL. Conselho Federal de Educação. Resolução nº 03, de 16 de junho de 1987. Fixa os mínimos de conteúdo e duração a serem observados nos cursos de graduação em Educação Física (Bacharelado e/ou Licenciatura Plena). Diário Oficial da União. Brasília-DF, 1987.

BRASIL. Conselho Federal de Educação. Resolução CNE/CP No 2. Institui a duração e a carga horária dos cursos de licenciatura, de graduação plena, de formação de professores da Educação Básica em nível superior. Diário Oficial da União: Seção 1, Brasília-DF, 4. Mar. 2002.

BRASIL. Conselho Nacional de Educação. Resolução n ${ }^{\circ}$ 02. Define as Diretrizes Curriculares Nacionais para a formação inicial em nível superior (cursos de licenciatura, cursos de formação pedagógica para graduados e cursos de segunda licenciatura) e para a formação continuada. Diário Oficial da União: Seção 1, Brasília-DF, 2. Jul. 2015.

BRASIL. Lei $\mathrm{n}^{\circ}$ 9.696, de 1 de setembro de 1998. Dispõe sobre a regulamentação da Profissão de Educação Física e cria os respectivos Conselho Federal e Conselhos Regionais de Educação Física. Diário Oficial da União: Seção 1, Brasília-DF, 2. Set. 1998

CONSELHO FEDERAL DE EDUCAÇÃO FÍSICA - CONFEF. Estatuto do Conselho Federal de Educação Física, 2010. Disponível em: http://www.confef.org.br/confef/conteudo/471 Acesso em: 24 out. 2017.

FREITAS, Washington D.F. A importância do profissional de educação física na orientação da musculação. 2013. 40 f. Trabalho de Conclusão de Curso (Bacharelado em Educação Física - Centro Universitário de Formiga, Formiga, 2013.

MONTEIRO, Luciana Z. Perfil da Atuação do Profissional de Educação Física junto aos portadores de Diabetes Mellitus nas Academias de Ginástica de Fortaleza. 2006. 89 f. Dissertação (Mestrado em Educação em Saúde) - UNIFOR, Fortaleza, 2006.

NAHAS, Markus V. Atividade, saúde e qualidade de vida: conceitos e sugestões para um estilo de vida ativo. 2. ed. Londrina, PR: Midiograf, 2001.

NOZAKI, Hajime T. Educação Física e reordenamento no mundo do trabalho: mediações da regulamentação da profissão.2004. 399 f. Tese de doutorado (Doutorado em Educação) - Faculdade de Educação, Universidade Federal Fluminense, Niterói, 2004.

PALMA, Alexandre et al. Trabalho e saúde: o caso dos professores de educação física que atuam em academias de ginástica. Cadernos IPUB (UFRJ), Rio de Janeiro, v. XIII, p. 11-30, 2007.

PRONI, Marcelo. W. Universidade, profissão Educação Física e o mercado de trabalho. Motriz, Rio Claro, SP, v.16, n.3, p.788-798, jul./set., 2010.

RIBEIRO, Silvia R. Perspectivas de atuação do profissional de educação física: perfil de habilidades no atual contexto de mercado e formação inicial. In: Encontro Latino Americano de Iniciação Científica e VIII Encontro Latino Americano de Pós-Graduação, 13., 2018. Anais [...] - São José dos Campos: Universidade do Vale do Paraíba, 2008. 
SIMON, Felipe C. Técnica de Musculação: guia passo a passo totalmente ilustrativo. São Paulo: Câmara Brasileira do Livro, 2007.

SEVERINO, Antonio J. Metodologia do Trabalho Científico. São Paulo: Cortez, 2007.

SOUZA, Josiane Vieira; BASTOS, Thaisnara Priscila Franco; OLIVEIRA, Maria de Fatima Alves. Perfil dos alunos universitários dos cursos de educação física e fisioterapia em relação à alimentação e a atividade física. Práxis, v. 6, n. 11, p. 103-113, 2014.

VAGO, Tarcísio M. Início e fim do século XX: Maneiras de fazer educação física na escola. Cadernos Cedes, ano XIX, no 48, Ago. 1999.

VELOSO, Waldir P. Metodologia do Trabalho Científico: normas técnicas para a redação de trabalho científico. 2. ed. Curitiba: Jaruá, 2011.

\section{Como citar este artigo}

LOBO, A. M.; BARROS, G. S.; OLIVEIRA, P. S. P.; TRIANI, F. S. Formação universitária e trabalho: áreas de atuação desejadas por estudantes de educação física. Revista Kinesis, Santa Maria, v. 38, p. 01-11, 2020.

* O presente trabalho não contou com apoio financeiro de nenhuma natureza para sua realização. 